\title{
Characteristics of men who have sex with men (MSM) who tested for HIV while donating blood in Latvia
}

\author{
A Mozalevskis $^{1 *}$, A Karnite ${ }^{2}$ \\ From International Symposium HIV and Emerging Infectious Diseases 2014 \\ Marseille, France. 21-23 May 2013
}

\section{Background}

In 2005, Latvia lifted the ban on blood donation for men who have sex with men (MSM). The prevalence of HIV infection in blood donations since then has been stable (around $0.02 \%$ ), though it is higher than the European average $(0.009 \%$ in 2006). We aim at describing the MSM who report that their last HIV test was done while donating blood (WDB) to approach the role of MSM in the donor blood safety.

\section{Methods}

We used the Latvian dataset from the European MSM Internet Survey (EMIS, 2010). We compared the MSM who had their last HIV test WDB with those who had their last HIV test elsewhere in terms of socio-demographic and behavioral factors using Chi-square and Fisher's exact tests.

\section{Results}

Of 708 EMIS respondents in Latvia, 346 (49.8\%) ever tested for HIV and of these, 46 (13.3\%) received their last HIV test WDB. Reactive HIV test were lower among MSM who reported having last test WDB than elsewhere ( $4 \%$ vs. $8 \% \mathrm{p}=0.292$ ). Respondents below 25 years, MSM self-identified as bisexual rather than gay and MSM who were less open about their sexual orientation were more likely to have their last HIV test WDB (25\% vs. $11 \%$, $\mathrm{p}=0.003 ; 22 \%$ vs. $11 \%, \mathrm{p}=0.066 ; 15 \%$ vs. $5.5 \% \mathrm{p}=0.061$, respectively). There was no difference in terms of reported risk behavior. Only one respondent who received last HIV test WDB (2\%) reported having the opportunity to discuss sexual practices before the test

${ }^{1}$ National Center of Epidemiology (CNE), Salud Carlos III Institute, Madrid, Spain

Full list of author information is available at the end of the article while they were $48(16 \%)$ among those tested elsewhere $(\mathrm{p}=0.047)$.

\section{Conclusion}

MSM donate blood and the prevalence of HIV infection in blood donation from MSM might be higher than from general population. MSM who donate blood are younger, self-identified as bisexual and not open about their sexual orientation. More attention is needed to evaluate their sexual risk behaviors in a sensitive and acceptable way during the pre-donation interview.

\section{Authors' details}

${ }^{1}$ National Center of Epidemiology (CNE), Salud Carlos III Institute, Madrid, Spain. ${ }^{2}$ Riga Stradins University, Department of Public Health and Epidemiology, Riga, Latvia.

Published: 23 May 2014

doi:10.1186/1471-2334-14-S2-P10

Cite this article as: Mozalevskis and Karnite: Characteristics of men who have sex with men (MSM) who tested for HIV while donating blood in Latvia. BMC Infectious Diseases 2014 14(Suppl 2):P10.

Submit your next manuscript to BioMed Central and take full advantage of:

- Convenient online submission

- Thorough peer review

- No space constraints or color figure charges

- Immediate publication on acceptance

- Inclusion in PubMed, CAS, Scopus and Google Scholar

- Research which is freely available for redistribution 